\title{
APLIKASI PRESENSI MAHASISWA DENGAN MENGGUNAKAN QR CODE BERBASIS ANDROID PADA UNIVERSITAS BINA DARMA
}

\author{
Muhamat Al Satrio ${ }^{1}$, Leon Andretti Abdillah ${ }^{2}$, Ahmad Syazili $^{3}$ \\ ${ }^{1,2}$ Program Sutdi Sistem Informasi, Universitas Bina Darma \\ ${ }^{3}$ Program Studi Teknik Informatika, Universitas Bina Darma \\ ${ }^{1,2,3}$ Jalan Ahmad Yani No.3, Plaju, Palembang \\ ${ }^{1}$ satriorio44@gmail.com, ${ }^{2 *}$ leon.abdillah@yahoo.com
}

\begin{abstract}
Presence is one of the important factors in the university because students' attendance can support learning activities, especially at Bina Darma University. Problems that occur at this moment are in the data present student data, where the persistent system still using paper media (paperbased). This method has a weakness that is with the absent label performed by students. There for we need to build student attendance system. By utilizing QR Code technology, student data can be stored in the form of QR Code images that will be affixed / attached to Student Identity Card $(K T M)$. Then the presence process is done through the presence of $Q R$ Code applications on smartphones that have been installed (installed) by all lecturers. And finally, the data is submitted to the media information presence University of Bina Darma through internet.
\end{abstract}

Keywords: Android, QR Code, Presence, KTM, Smartphone.

\section{PENDAHULUAN}

Pada masa sekarang ini, perkembangan Teknologi Informasi (TI) digunakan untuk memberikan kemudahan, mempercepat dan meningkatkan efisiensi pekerjaan suatu organisasi atau perusahaan. Perkembangan teknologi juga merambah pada teknologi mobile (Sari, Abdillah, \& Wardhani, 2016). Teknologi mobile telah menjadi bagian kehidupan kita sehari-hari. Hampir semua kalangan masyarakat memiliki telepon seluler, personal digital assistant (PDA) atau sejenisnya yang mereka gunakan untuk berkomunikasi lewat suara, memeriksa email atau manfaat teknologi lainnya (Abdillah, 2016). Android adalah platform open source yang komprehensif yang dirancang untuk perangkat mobile (L. N. Sari, Abdillah, \& Muzakir, 2015) dan bagi para pengembangnya untuk menciptakan aplikasi mereka sendiri untuk digunakan oleh bermacam-macam piranti bergerak (Husodo, 2013).

Pemanfaatan TI tersebut salah satunya dimanfaatkan untuk membantu pencatatan kehadiran atau presensi di suatu organisasi atau perusahaan dengan menggunakan "QR (Quick Response) codes" atau "QR-Code" atau kode batang untuk membaca suatu identitas. QR Code adalah sebuah kode batang dua dimensi yang ditemukan oleh sebuah perusahaan Jepang bernama Denso Wave pada tahun 1994. $Q R$ Code ini adalah pengembangan dari kode batang sebelumnya. Pada model barcode lama, data disimpan secara horizontal saja, sedangkan pada $Q R$ Code, data disimpan baik secara vertikal maupun horizontal. QR Code adalah jenis kode batang matriks (Lorenzi, Vaidya, Chun, Shafiq, \& Atluri, 2014) atau meiliki 2 (dua) dimensi (Abdillah, 2014). QR Code telah ditemukan untuk melacak komponen otomotif di pabrik manufaktur dan semakin banyak menemukan jalan mereka ke ruang perkotaan dan perangkat mobile (Krombholz et al., 2014). QR Code (Gambar 2) memiliki keunggulan dibandingkan dengan jenis-jenis barcode lainnya (Gambar 1), yaitu informasi dikodekan dalam arah vertikal dan horizontal, sehingga menyimpan data beberapa ratus kali lebih banyak daripada kode batang tradisional (Kieseberg et al., 2010). QR Code menyediakan sejumlah fitur (Denso Wave, 2011) berikut: 1) Pengkodean Kapasitas Tinggi, 2) Ukuran Cetakan Kecil, 3) Kemampuan Kanji dan Kana, 4) Tahan dan Kerusakan Tahan, 5) Dapat dibaca dari berbagai arah dalam $360^{\circ}$, dan 6) Fitur Pembuatan Terstruktur. Pada fitur $Q R$ Code, data mahasiswa akan dapat disimpan dalam bentuk gambar $Q R$ Code yang akan ditempelkan / dilekatkan di kartu tanda mahasiswa (KTM). 


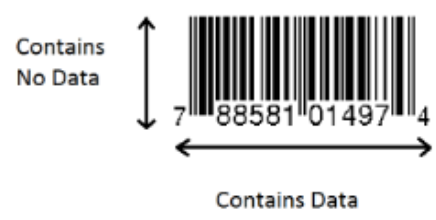

Gambar 1. Barcode.

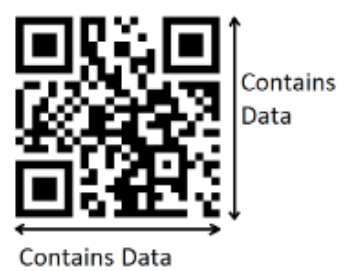

Gambar 2. QR Code.

Presensi adalah suatu pendataan kehadiran, bagian dari pelaporan aktivitas suatu institusi, atau komponen institusi itu sendiri yang berisi data kehadiran yang disusun dan diatur sedemikian rupa sehingga mudah untuk dicari dan dipergunakan apabila sewaktu-waktu diperlukan oleh pihak yang berkepentingan (Purwanto, 2009). Presensi menjadi salah satu faktor yang penting di universitas karena presensi dapat menunjang kegiatan perkuliahan. Sistem presensi yang umumnya diterapkan selama ini adalah terletak pada pengumpulan data-data hadir mahasiswa yang dilakukan di dalam kelas, di mana sistem persensi tersebut yang sedang berjalan masih menggunakan media kertas (paper based) untuk pencatatan presensi. Metode ini mempunyai kelemahan yaitu dengan adanya penitipan absen yang dilakukan oleh mahasiswa, menghabiskan biaya pengeluaran (cost) untuk pembelian kertas dan tinta, dan perlunya rekapitulasi presensi setiap bulannya yang menghabiskan waktu dan tenaga. Oleh karena itu, perlunya pengembangan sistem presensi mahasiswa dengan metode selain paper based. Bagaimana dengan penggunaan alat presensi dengan sidik jari. Penggunaan alat presensi dengan sidik jari (fingerprint) juga tidak cukup praktis dan ekonomis karena untuk harga satu unit alat fingerprint menghabiskan dana sekitar 1 juta sampai 5 juta rupiah. Bayangkan jika kelas yang dipunyai suatu universitas itu sangat banyak, sehingga akan menghabiskan dana yang cukup besar. Di tambah lagi, perlunya integrasi dari sistem presensi paper based ke sistem presensi fingerprint based yang diharuskan melakukan pendataan sidik jari seluruh mahasiswa, sehingga menyebabkan kurang praktisnya sistem tersebut dalam penerapannya.

Berdasarkan uraian diatas, maka penulis tertarik untuk membuat sebuah perangkat lunak sistem presensi dengan $Q R$ Code pada aplikasi presensi mahasiswa berbasis Android pada Universitas Bina Darma Palembang.

\section{METODOLOGI PENELITIAN}

Pada bagian ini, penulis akan menguraikan sejumlah hal yang digunakan dalam pelaksanaan penelitian ini, antara lain: 1) Lokasi penelitian, 2) Metode pengumpulan data, dan 3) Metode pengembangan sistem atau perangkat lunak.

\subsection{Lokasi Penelitian}

Lokasi penelitian dilakukan penulis di Universitas Bina Darma PalembangJl. Jend. A. Yani No.03, Seberang Ulu I, Kota Palembang, Surmatera Selatan, Indonesia. Waktu penelitian dilakukan pada bulan Maret 2016 sampai dengan bulan Juli 2016.

\subsection{Metode Pengumpulan Data}

Metode pengumpualn data yang digunakan dalam penelitian ini adalah: 1) Dokumentasi. Dokumen merupakan catatan peristiwa yang sudah berlalu (Sugiyono, 2013). Dokumetasi merupakan suatu cara pengumpulan data yang diperoleh dari dokumen-dokumen yang ada atau catatan-catatan yang tersimpan, baik itu berupa catatan transkrip, buku, surat kabar, dan lain sebagainya. Disini penulis mengambil data melalui dokumen presensi mahasiswa, data kemahasiswaan, jurnal tentang presensi, 2) Wawancara. Wawancara merupakan pertemuan dua orang untuk bertukar informasi dan ide melalui tanya jawab, sehingga dapat dikontruksikan makna dalam suatu topik tertentu (Sugiyono, 2013). Pengambilan data melalui wawancara ataupun secara lisan langsung dengan sumber datanya, baik melalui tatap muka atau lewat telephone, teleconference. Di sini, peneliti melakukan sesi wawancara dengan pegawai bagian kemahasiswaan dan unit pelayanan teknis (UPT) di Universitas Bina Darma secara langsung. Wawancara yang dilakukan peneliti bersifat bebas, yaitu peniliti tidak menggunakan pedoman wawancara khusus yang berisikan pertanyaan-pertanyaan yang spesifik, dan hanya menanyakan poin-poin yang penting saja yang ingin digali lebih jauh oleh peneliti di bagian kemahasiswaan dan UPT di Universitas Bina Darma, 
3) Studi Pustaka. Studi Pustaka adalah suatu cara pengumpulan data dengan cara menghimpun informasiinformasi yang relevan dengan topik atau masalah yang diteliti (Harahap, 2014). Peneliti mendapatkan data-data tersebut dari buku-buku pembuatan $Q R$ Code, masalah-masalah dan informasi tentang presensi dan teknologi informasi di android, dan 4) Observasi. Observasi adalah suatu cara pengumpulan data dengan cara mengamati dan mengawasi serta merekam semua kejadian/fenomena-fenomena yang terjadi (Sugiyono, 2013). Peneliti melakukan observasi ke Universitas Bina Darma Palembang bagian UPT dengan cara mengamati dan mengawasi dan merekam apa yang mereka lakukan sehingga didapatkan sebuah kesimpulan yang tentang bahan-bahan dan cara implementasi presensi mahasiswa dengan $Q R$ Code berbasis android tersebut.

\subsection{Metode Pengembangan Sistem}

Metode pengembangan sistem yang digunakan dalam penelitian ini adalah model waterfall. Model waterfall (Pressman, 2010) terdiri atas sejumlah kegiatan, yaitu: 1) Communication, 2) Planning, 3) Modeling, 4) Construction, dan 5) Deployment.

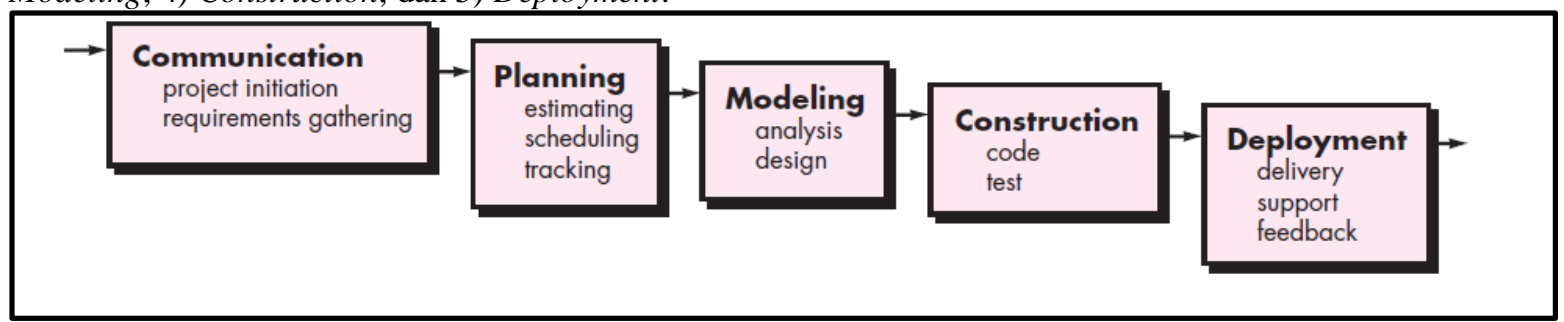

Gambar 3. Model Waterfall.

\section{HASIL}

Berisi hasil penelitian. Hasil penelitian dapat dilengkapi dengan tabel, grafik, atau gambar. Bagian pembahasan memaparkan hasil pengolahan data, interpretasi hasil penelitian yang diperoleh, mengaitkan dengan sumber rujukan yang relevan.

\subsection{Halaman Utamma}

Metode pengembangan sistem yang digunakan dalam penelitian ini adalah model waterfall. Model waterfall terdiri atas sejumlah kegiatan, yaitu: 1) Home, 2) Data Dosen, 3) Data Mahasiswa, 4) Data Mata Kliah, 5) Data Jadwal, 6) Cetak QR Code.

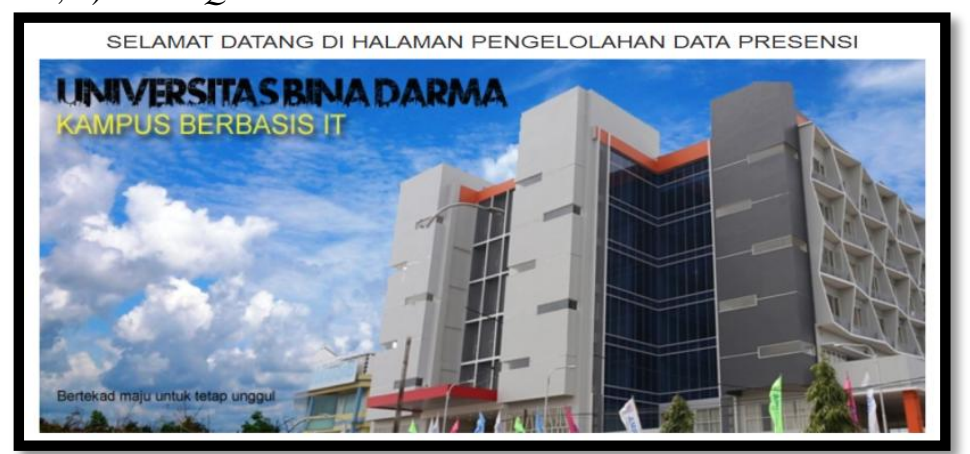

Gambar 4. Model Waterfall.

\subsection{Halaman QR Code Mahasiswa}

Halaman $Q R$ Code adalah halaman yang akan tampil apabila admin telah melakukan cetak $Q R$ Code mahasiswa maka sistem akan menampilkan $Q R$ Code per mahasiswa. Lihat gambar 5 untuk melihat halaan $Q R$ Code mahasiswa. 


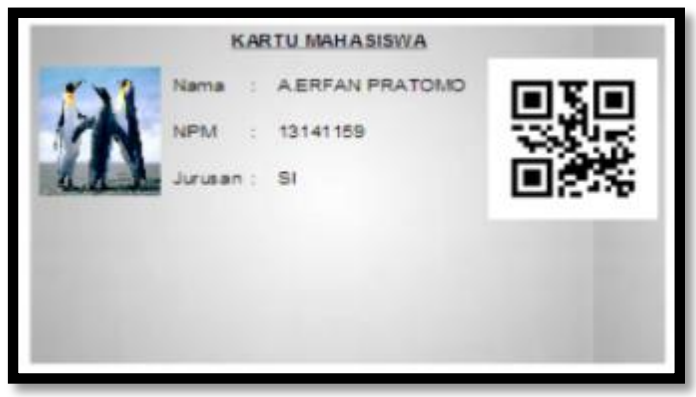

Gambar 5. Model Waterfall.

\subsection{Halaman Login dan Android Dosen}

Halaman login android adalah halaman yang digunakan dosen pada saat login dan melakukan presensi di dalam kelas, karena scan barcode di lakukan menggunakan android. Setelah dosen berhasil masuk ke dalam sistem maka sistem akan menampilkan halaman utama dosen versi android. Lihat gambar 6 untuk melaihat tampilan halaman login dosen.

Halaman index dosen didalam android adalah halaman yang tampil pada saat dosen melakukan login dengan cara meng-input-kan username dan password yang benar dan sistem akan menampilkan halaman index dosen versi android. Lihat gambar 7 untuk melihat halaman index dosen android.

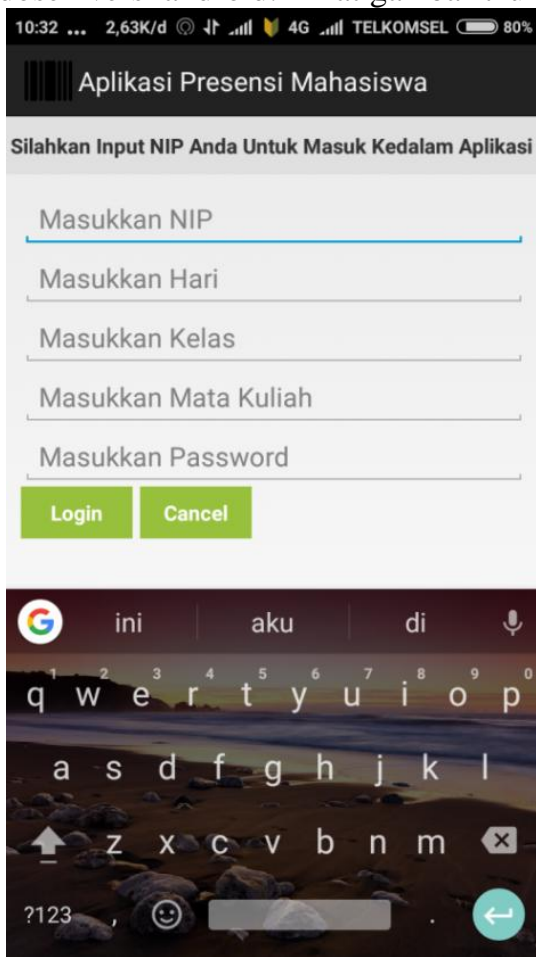

Gambar 6. Halaman Logn Dosen.

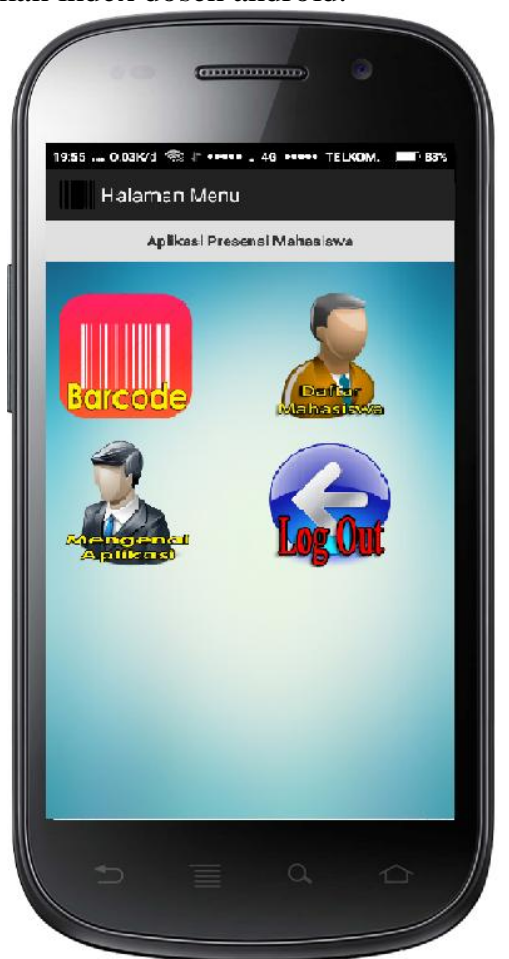

Gambar 7. Halaman Index Dosen Android.

\subsection{Halaman Scan QR Code dan Daftar Nama Mahasiswa}

Halaman scan $Q R$ Code adalah halaman yang digunakan untuk menangkap $Q R$ Code mahasiswa oleh dosen ketika melakukan presensi. Setelah data mahasiswa di-scan, maka dosen dapat melihat daftar mahasiawa yang telah hadir. 


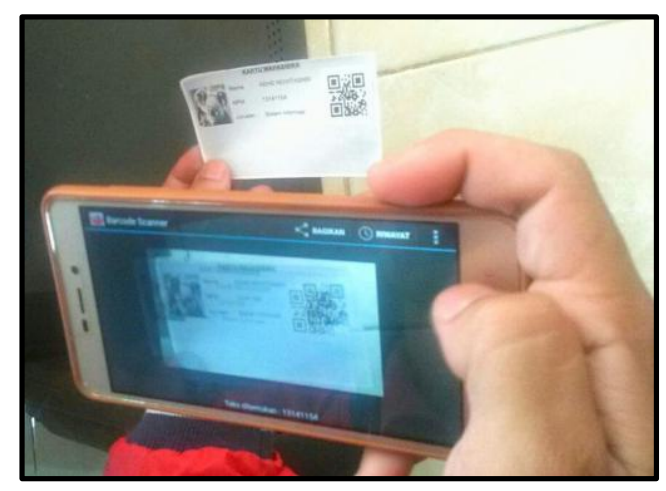

Gambar 8. Tampilan $Q R$ Code Kartu Mahasiswa.

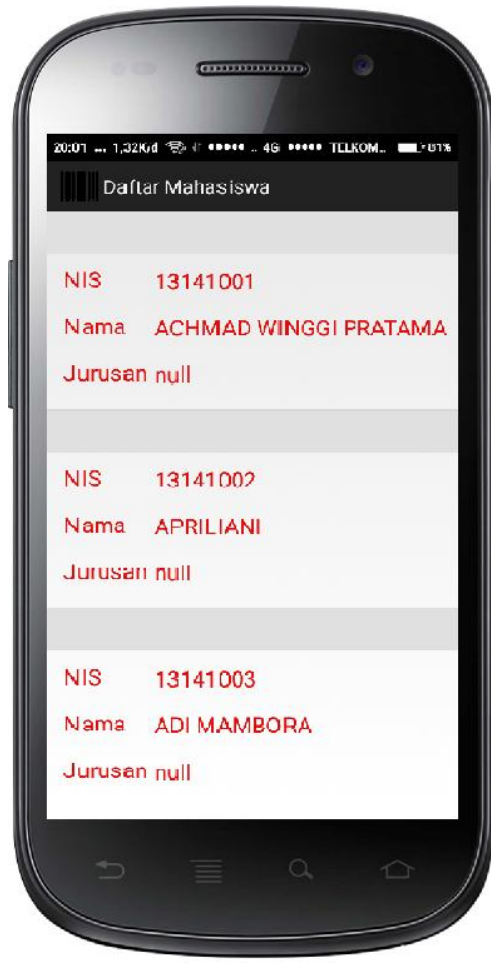

Gambar 9. Daftar Hadir Mahasiswa

\subsection{Laporan Daftar Hadir Mahasiswa}

Halaman laporan absensi per mata kuliah adalah halaman yang tampil setelah dosen melakukan presensi dan dosen melihatnya berdasarkan mata kuliah yang telah di lakukan presensi (Gambar 10). Untuk melihat daftar mahasiswa yang terlambat bisa dilihat pada gambar 11 .

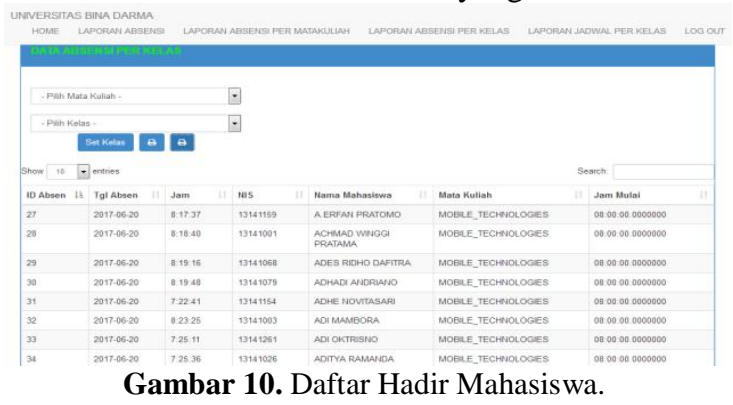

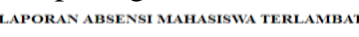

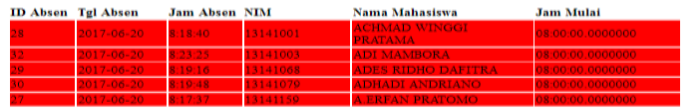

Gambar 11. Daftar Mahasiswa Terlambat.

\section{SIMPULAN}

Berdasarkan hasil kegiatan penelitianyang telah diuraikan pada bagian-bagian diatas, maka dapat diambil sejmlah kesimpulan sebagai berikut:

1) Dengan adanya aplikasi presensi menggunakan $Q R$ Code ini dapat memudahkan pekerjaan dosen karena hanya dengan cara melakukan scanning $Q R$ Code untuk melakukan presensi terhadap kehadiran mahasiswa.

2) Aplikasi ini menggunakan $Q R$ Code untuk membuat kode setiap mahasiswa sehingga setaip mahasiswa mempunyai code untuk data diri mahasiswa.

3) Presensi di lakukan berdasarkan jadwal kuliah dan jam yang sama, jika terjadi keterlambatan maka sistem akan memberitahu dengan tanda bewarna merah.

4) Penulis memberikan saran-saran yang kiranya berguna bagi Universitas Bina Darma adalah sebagai berikut: a) Aplikasi ini sangat berguna jika di gunakan karena telah menggunakan perkembangan teknologi $Q R$ Code sehingga akan menambah nilai untuk Universitas Bina Darma di mata masyarakat, 
dan b) Apabila sistem informasi ini telah banyak digunakan pelanggan maka lakukanlah maintenance agar tidak mengalami gangguan pada saat di gunakan oleh pengguna sistem.

\section{DAFTAR PUSTAKA}

Abdillah, L. A. (2014). Data Structures \& Algorithms. Retrieved from http://blog.binadarma.ac.id/mleonaa/teaching/programming/data-structures/

Abdillah, L. A. (2016). Ujian Online Mahasiswa Ilmu Komputer Berbasis Smartphone. Paper presented at the Seminar Nasional Riset Ilmu Komputer Ke-2 (SNRIK2016), Makassar.

Denso Wave. (2011). What is a QR Code? , from http://www.qrcode.com/en/about/

Harahap, N. (2014). Penelitian Kepustakaan. Jurnal Iqra', 8(1), 68-73.

Husodo, H. C. (2013). Perancangan Sistem Aplikasi Lelang Barang Berbasis Android. Universitas Muhammadiyah Malang, Malang.

Kieseberg, P., Leithner, M., Mulazzani, M., Munroe, L., Schrittwieser, S., Sinha, M., \& Weippl, E. (2010). QR code security. Paper presented at the Proceedings of the 8th International Conference on Advances in Mobile Computing and Multimedia.

Krombholz, K., Frühwirt, P., Kieseberg, P., Kapsalis, I., Huber, M., \& Weippl, E. (2014). QR code security: A survey of attacks and challenges for usable security. Paper presented at the International Conference on Human Aspects of Information Security, Privacy, and Trust.

Lorenzi, D., Vaidya, J., Chun, S., Shafiq, B., \& Atluri, V. (2014). Enhancing the government service experience through QR codes on mobile platforms. Government Information Quarterly, 31(1), 616.

Pressman, R. S. (2010). Software Engineering: A Practitioner's Approach (7th ed.). New York, US: McGraw-Hill.

Purwanto. (2009). Evaluasi Hasil Belajar. Surakarta: Pustaka Belajar.

Sari, I. O., Abdillah, L. A., \& Wardhani, K. R. N. (2016). Application Location Based Service (LBS) Location Search Palembang Nature-Based Android. Paper presented at the The 5th International Conference on Information Technology and Business Application (ICIBA2016), Bina Darma University, Palembang.

Sari, L. N., Abdillah, L. A., \& Muzakir, A. (2015). Geographic information systems of android-based residential locations. Paper presented at the The 4th International Conference on Information Technology and Engineering Application (ICIBA2015), Bina Darma University, Palembang.

Sugiyono. (2013). Metode Penelitian Pendidikan. Bandung: Alfabeta. 